\title{
OPTILAAL LOCATIOTN OF
}

\section{SCHOOL FACILITIES}

J. D. COELHO

Working Paper $n^{0.92 / 3}$

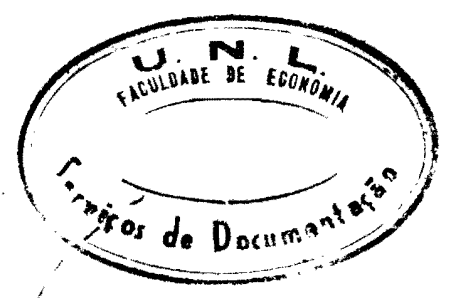

UNIVERSIDADE NOVA DE LISBOA

Faculdade de Economia

Travessa Estevão Pinto

1000 LISBOA

PORTUGAL

Julho 1988 


\title{
OPTIMAL LOCATION OF SCHOOL FACILITIES
}

\begin{abstract}
AESTRACT
A project involving the development of a relational data base of educational information at a national level for Portugal and the optimization of school facilities is described. A few new theoretical developments in relation with facility location modelling are mentioned. Information regarding our experience is provided.
\end{abstract}

Keywords: schools location, relational data base, discrete programming, multi-criteria analysis. 


\section{THE PROBLEM}

The location of educational facilities may be formulated in many different ways depending how the main components are considered and the nature of the decision process whose optimal solution is pursued.

A most typical approach (see, for example, Balinski, 1961; Hakimi, 1964; Revelle and Swain, 1970; Leonardi, 1978; Laporte, 1987) consists in assuming the study area divided into zones with the demand in each.zone concentrated in one of its central points and a number of potential facility location sites that may coincide or note with the demand points. The optimization is accomplished by finding out which potential location sites offer greatest benefit according to the criteria assumed and the constraints placed to bind the feasible region. In this way, no consideration is given to existing facilities and an optimal set of new facilities would be provided.

In real life the scenario above is, however, very seldom found in the educational facility location context. It is uncommon that no facility of the type for which the optimization procedure is set up will exist in the study area. The location of educational facilities is often confined to marginal improvements to an existing situation, that may consist in opening some new facilities, closing a few others, increasing or decreasing capacities by transforming available spaces or adapting the facilities to different uses.

Another aspect that has started receiving attention (Laporte and Nobert, 1981; Branco and Coelho, 1986) is the joint location of facilities and routing of users (or goods, in different settings). The routing/location problem has a special relevance in low density regions where the attraction area for a facility can be quite extensive. Important savings may be obtained by having fewer facilities and school buses collecting facility users if a joint optimization is accomplished.

In the educational facility location modelling, we note that four main objectives are pursued:

1. Providing education services at full population coverage, this means ascribing a school to every student having in account some maximun distance or travel time constraints; 
2. Minimization of overall costs - these include set up costs for new facilities, location dependant operation and transportation costs for open facilities and costs assigned to closing downs;

3. Maximization of users benefit - a measure of user benefit usually related to accessibility and therefore dependant on the location of facilities.

4. Political objectives - these are often ill-defined but, for example, may take the form of maximization of the voting population in the communities where new school are built or upgraded.

In addition, the constraints binding the optimization search are the balance between demand and supply for educational services, maximum distance or travel time imputed to users, budget and eventually some extra planning constraints. 


\section{MODELS}

We carry on a brief review of optimization combinatorial nodels that fit to the location of educational facilities and point out some adjustments that make them more adequate to the peculiarities of the real world problems in the educational field that have been mentioned previously. The review will cover the following models:
A. Simple Facility Location Mode!
B. P-Median
C. Capacitated Facility Location Model
D. Surplus Maximization Capacitated Facility Location Model
E. Covering Location Model
F. Maximal Covering Location Model
G. Hamiltonean P-Median Model
H. Routing Location Models

The notation adopted in the formulation of the models is as follows:

I - set of indices of zones

$\mathrm{J}$ - set of indices of potential facility sites

$\mathrm{J}_{0}$ - set of indices of facility location sites fixed 'closed'

$\mathrm{J}_{1}$ - set of indices of facility location sites fixed 'open'

$\mathrm{J}_{\mathfrak{d}}$ - set of indices of facility location sites subject to the decision process of open/close

P - total number of users in the study area.

$p_{i}$ - number of users in zone $i$

$y_{j}$ - boolean variable assigned to facility $j$

$y_{j}$ - is equal to one if site $j$ is used to locate a facility and zero otherwise

$y$ - vector for location variables $y_{j}, j \in J$ 
$\mathrm{y}_{0}$ - vector of location variables $\mathrm{y}_{\mathrm{j}}, \mathrm{j} \in \mathrm{J}_{0}$.

$y_{1}$ - vector of location variables $y_{j}, j \in J_{1}$

$y_{d}$ - vector of location variables $y_{j}, j \in J_{d}$

$\ell_{j}-$ minimum size of the facility at site $j$

$u_{j}$ - maximum capacity of the facility at site $j$

$t_{i j}$ - flow of users from zone $i$ to facility $j$

$x_{i j}$ - proportion of users from zone $i$ assigned to facility $j$

$c_{i j}$ - 'generalized cost of assigning a user of zone $i$ to a facility $j$

$f_{j}$ - set up cost for facility $i$

$\mathbf{f}_{0 j}$ - cost of closing down facility $j$

$f_{1 j}$ - cost of opening or maintaining open facility $j$

$A, B$ - matrices of coefficients of planning constraints

b - vector rhs of planning constraints

$\bar{t}_{i j}$ - apriori probability that users from zone i select facility $j$ 


\section{A - SIMPLE FACILITY LOCATION MODEL}

The simple (uncapacitated) facility location model was put forward by Balinski (1961) and received many contributions until a very efficient dual based solution method was proposed by Bilde and Krarup (1977) and Erlenkotter (1978). The simple facility location model is formulated as follows:

(A.1)

$$
\operatorname{Min}_{t, y} Z-\sum_{i j} c_{i j} t_{i j}+\sum_{j} f_{j} y_{j}
$$

subject to

(A.2)

$$
\sum_{j} t_{i j}=p_{i}
$$

ie I

(A.3)

$$
t_{i j} \leq p_{i} y_{j}
$$

(A.4)

$$
t_{i j} \geq 0
$$

$$
i \in I, j \in J
$$

(A.5)

$$
y_{j}=0,1
$$

In this formulation, constraint (A.2) indicates that all users are assigned to a facility and constraint (A.3) prevents users to be allocated to a closed facility. The objective is the minimization of sat up costs for "open facilities" and the overall location dependant costs of serving users at facilities. An alternative formulation involving variables $x_{i j}$ defined as

$$
\mathbf{x}_{\mathrm{ij}}=\frac{\mathbf{t}_{\mathrm{ii}}}{\mathrm{p}_{\mathrm{i}}}
$$

and cost parameters $c^{\prime} i j=c_{i j} p_{i}$ consists of:

(A.6)

$$
\operatorname{Miq}_{(x, y)} Z=\sum_{i j} c_{i j}^{\prime} x_{i j}+\sum_{j} f_{j} y_{j}
$$

subject to

(A.7)

$$
\sum_{\mathbf{j}} \mathbf{x}_{\mathrm{ij}}=1
$$

i. 1

(A.8)

$$
x_{i j} \leq y_{j}
$$

(A.9)

$$
x_{i j} \geq 0
$$$$
i \in I, j \in J
$$ 
(A.10) $y_{j}=0,1$

$j \in J$

Since no capacity constraint are considered in the formulations above it is easy to conclude that variables $x_{i j}$ are at optimality either zero or one, and therefore users in the same zone are assigned to a single facility.

A step forward is achieved considering the vector $y=\left(y_{1}, y_{0}, y_{d}\right)$ and introducing the costs for closing down facilities. The model is than formulated as follows:

(A.11)

$$
\operatorname{Min}_{\left(x, y_{d}\right)} Z=\sum_{i j} c_{i j}^{\prime} x_{i j}+\sum_{j} f_{1 j} y_{j}+\sum_{j} f_{0 j}\left(1-y_{j}\right)
$$

subject to constraints (A.7) - (A.9) and

$$
y_{j}=0,1
$$

$$
j \in J_{d}
$$

The first term in the objective function denotes the location dependant operation and transportation costs, the second term the set up' costs for new facilities and the last one the costs assigned to closing down facilities. 


\section{B - P-MEDIAN}

The concept of p-median on a graph was introduced by Hakimi (1964) and since then the p-median model for facility location has attracted considerable attention. In this sodol, the number of facilitics is fixed to $\mathrm{p}$ and total overall costs are minimized. A concise formulation is obtained if it is considered $J \subseteq \dot{I}$ and assigned $x_{j j}=1$ if a facility is located at site $j$. The $p$-median model is formulated as follows:

(B.1)

$$
\operatorname{Min}_{(\mathrm{x})} Z=\sum_{\mathrm{ij}} c^{\prime} \mathbf{i j} \mathbf{x}_{\mathrm{ij}}+\sum_{\mathbf{j}} \mathbf{f}_{\mathbf{j}} \mathbf{x}_{\mathrm{ij}}
$$

subject to

(B.2)

$$
\sum_{j} x_{i j}=1
$$

$$
\mathbf{x}_{\mathrm{ij}} \leq \mathbf{x}_{\mathrm{jj}}
$$

$$
\text { - i } \in I, j \in J
$$

(B.4)

$$
\sum_{j} x_{j i}=p
$$

$$
x_{i j}=0,1
$$

$$
j \in J
$$

Âs above, constraint (B.2) ensures that all users colls are allocated to a facility and (B.3) prevents allocation to closed facilities, while (B.4) fixes the number of facilities to $\mathrm{p}$. If it is assumed that facilities may also be shut down, then (B.1) is replaced by

$$
\operatorname{Min}_{(\mathbf{x})} Z=\sum_{\mathrm{ji}} c_{i j} \mathrm{x}_{\mathrm{ij}}+\sum_{\mathrm{j}} \mathrm{f}_{1 j} \mathrm{x}_{\mathrm{jj}}+\sum_{\mathrm{j}} \mathrm{f}_{0 j}\left(1-\mathrm{x}_{\mathrm{jj}}\right)
$$

A recent siudy of heuristic and exact methods to solve the p-median problem is provided by Captivo (1988). 


\section{C - CAPACITATED FACILITY LOCATION MODEL .}

A natural extension of the simple facility location model is achieved by considering constraints regarding the minimum size and maximum capacity of facilities. Adopting again the flow variables. $\left\{t_{i j}\right)$ extensively used in the geographical and transportation fields, the model is writlen down as:

$$
\operatorname{Min}_{t, y} Z=\sum_{j j} c_{i j} t_{i j}+\sum_{j} f_{1 j} y_{j}+\sum_{j} f_{0 j}\left(1-y_{j}\right)
$$

subject to

$$
\begin{aligned}
& \sum_{j} t_{i j}=p_{i} \\
& \ell_{j} y_{j} \leq \sum_{i} t_{i j} \leq u_{j} y_{j}
\end{aligned}
$$

j $\mathbf{~} \mathbf{J}$

$$
A t+B y z b
$$

$$
t_{i j} \geq 0, y_{j}=0,1
$$

iє I i j J

where (C.2) defines the demand for the facilities, (C.3) provides minimum size and maximum capacity bounds and (C.4) stands for any additional planning constraints.

This model was put forward by Balinski (1961) and received contributions, among others, by Kuehn and Hamburger (1963), Feldman, Lehrer and Ray (1\%6), Sá (1969), Akinc and Khumawala (1977), Geoffrion and Macbride (1978) and Van Roy (1986). This last author has proposed a very efficient algorithm based on a cross decomposition technique.

At this stage, we note that embedded in the simple facility location, p-median and capacitated facility location models is the linear transportation model. The behavioral assumption implicit there is that users select facility according to the minimum cost criterion. This is adequate when decision are taken centrally as in the transportation of goods. However, when individual users take their own decision on the facility where to go, some level of dispersion must be considered, since users may have many different reasons for deviating from the minimum cost alternative (Fig. 1 ). 


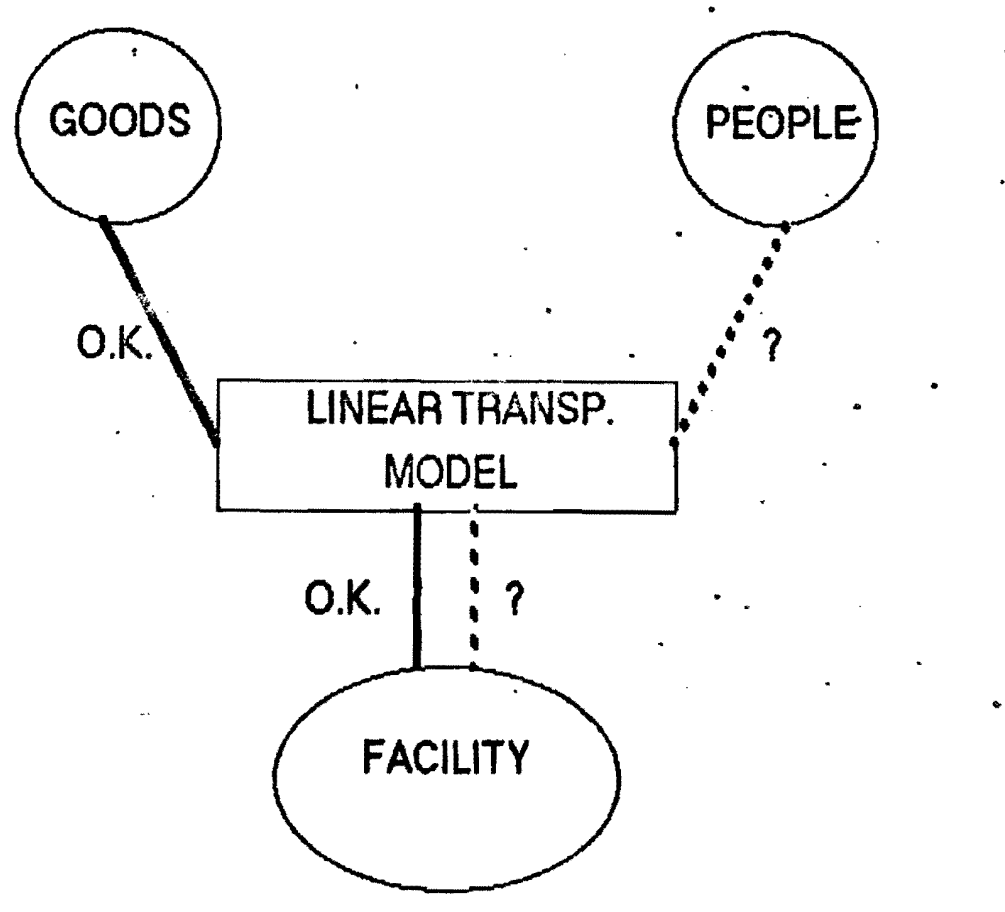

Fig. 1 - Facility location models with embedded linear , transportation sub-models 
D - SURPLUS MAXIMIZATION CAPACITATED FACILITY LOCATION MODEL

In this model proposed by Coelho (1980) the users' dispersion of preferences is incorporated by a gravity type transportation sub-model. The model is, as follows:

(D.1)

$$
\underset{(t, y)}{\max } S=-\frac{1}{\beta} \sum_{i j} t_{i j}\left(\log \frac{t_{i j}}{t_{i j}}-1\right)-\sum_{i j} c_{i j} t_{i j}-\sum_{j} f_{1 j} y_{j}-\sum_{j} f_{0 j}\left(i-y_{j}\right)
$$

subject to

(D.2)

(D.3)

$\ell_{j} y_{j} \leq \sum_{i} t_{i j} \leq u_{j} y_{j}$

$j \in J$

(D.4)

$A t+B y \geq b$

(D.5)

$y_{j}=0.1$

$\mathrm{j} \in \mathrm{J}$

It may be shown that the first two terms in the objective function are a measure of consumers' surplus associated to the gravity spatial demand model (Wilson et al (1981), Coelho (1983)). The objective function (D.1) is therefore an aggregate measure of locational surplus. Numerical experience is provided by Erienkotter and Leonardi (1981), Leonardi (1981) and Coelho (1988). 
E - COVERING LOCATION MODEL

The aim in this model is to locate facilities in such a way that every demand zone is 'covered', for example, at a maximum distance, time or generalized transportation cost. The model is written as follows:

(E.1)

$$
\operatorname{Min}_{(y)} Z=\sum_{j} f_{1 j} y_{j}+\sum_{j} f_{0 j}\left(1-y_{j}\right)
$$

subject to

$$
\sum_{j} a_{i j} y_{j} \geq 1
$$

$i \in 1$

$$
y_{j}=0 \text { or } 1
$$

$$
j \in J
$$

where

$$
a_{i j}= \begin{cases}1 & \text { if zone } i \text { is 'covered' by facility } j \\ 0 & \text { otherwise }\end{cases}
$$

The covering location model was put forward by Toregas et al (1971). It is a particular application of the set-covering problem, which has received very substantial attention in the literature (see, for example, Pierce (1968), Balas and Padberg (1972), Christofides and Hey (1978), Almeida, Paixão and Coelho (1982). A very efficient algorithm for large scale set-covering problems is given by Paizáo (1983). 
F - MAXIMAL COVERING LOCATION MODEL

Assume that from budgetary constraints or others, it is not possible to have more than $\mathrm{p}$ facilities which will not provide full population coverage. Then, the location of facilities that ensures maximal population covering is given by the maximal covering location model, proposed by Church and Revelle (1974), which is formulated, as follows:

(F.1)

$$
\operatorname{Max}_{(y, z)} Z=\sum_{i} p_{i} z_{i}
$$

subject to

(F.2)

$$
\sum_{j} a_{i j} y_{j} \geq z_{i}
$$

$$
i \in I
$$

(F.3)

$$
\sum_{j} y_{j}=p
$$

(F.4)

$$
y_{j}=0,1 \text { and } z_{i}=0,1
$$

$i \in I, j \in J$

where $z_{i}$ is a boolean variable that is equal to one if zone $i$ is 'covered' by at least one facility. The objective function corresponds to the maximization of the population covered by the facility set. Constraints (F.2) ensures that $z_{i}$ is equal to zero if no facility covers zone $i$ and constraints (F.3) fixes at $p$ the number of facilities. 
G - HAMILTONEAN P-MEDIAN MODEL

The Hamiltonean p-Median problem (HPMP) is a mixed location and routing apnroach proposed by Branco and Coelho (1934 and 1986) which embeds a joint routing and location optimization.

- It is clear that in school facility location it is essential to take into account simultaneously the locational aspects of the potential facility sites and the school buses routing.

Let $\mathrm{N}$ denote a set of potential facility sites and demand points. The Hamiltonean p-median problem consists in finding out p-Hamiltonean circuits serving all users in such a way that every user is assigned to a facility in the same circuit. This model is therefore an extension of the p-median and travelling salesman problems.

Several formulations for the HPMP may be considered (see Branco and Coelho (1984)) which may be explored for different solution methods. In particular. the HPMP can be formulated as follows:

$$
\operatorname{Min}_{x, y} Z=\sum_{k} \sum_{i j} c_{i j} x_{i j k}
$$

subject to

$$
\sum_{\mathbf{k}} \mathrm{y}_{\mathrm{ik}}=1
$$$$
i \in I
$$

$$
\sum_{\mathbf{i}} y_{i k} \geq 1
$$$$
k \in K
$$

$$
\sum_{i} x_{i j k}=y_{j k}
$$

$i \in I, k \in K$

$$
\sum_{j} x_{i j k}=y_{i k}
$$

$i \in I, k \in K$

$$
\sum_{i, j \in S} x_{i j k} \leq|S|-1
$$

$k \in \mathbb{K}$

where 
$y_{i k}= \begin{cases}1 & \text { if demand point } i \text { belongs to circuit } k \\ 0 & \text { otherwise }\end{cases}$

$x_{i j k}= \begin{cases}1 & \text { if demand point } i \text { precedes } j \text { in circuit } k \\ 0 & \text { otherwise }\end{cases}$

the cardinality of set $K$ is $p$ and $R_{k}=\left(i: y_{i k}=1\right)$ is the set of vertices in circuit $k$.

- Constraints (G.2) ensures that each demand point is assigned to a circuit, (G.3) defines $p$ circuits, (G.4) and (G.5) together with.(G.2) establishes that every demand points belongs to just one circuit and (G.6) prevents the existence of subcircuits in $\mathrm{R}_{\mathrm{k}}$. 


\section{H - ROUTING - LOCATION MODELS}

A more general setting regarding joint routing and location modelling than the one considered in the Hamiltonean p-median problem, would include multiple routes serving the facilities. The optimization process must obviously have into account, in this context, the location costs assigned to facilities and the transport cost associated with the routes that are designed to collect users. This framework is depicted in figure 2 diagrammatically.

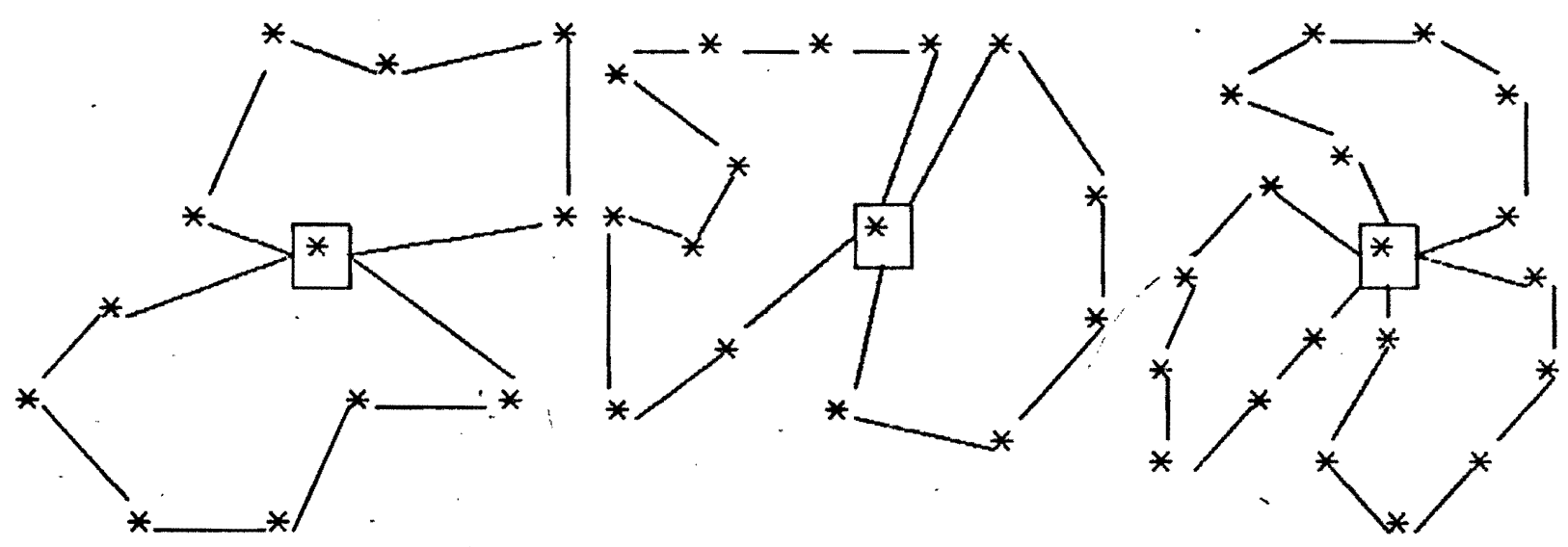

* demand point

$\square$ facility site

- arc in a route

Fig. 2 - Routing-Location Diagram

A recent survey of routing location problems is given by Laporte (1987). A particular routing location model for just one facility and $\mathrm{m}$ routes is studied by Laporte and Norbert (1981). It corresponds to the following formulation:

$$
\operatorname{Min}_{x, y} Z=\sum_{i j i} c_{i j} u_{i j}+\sum_{j} f_{j} y_{j}
$$

subject to

(H.2) $\quad \sum_{j} y_{j}=1$ 
(H.3)

$$
\sum_{i<j} u_{i j}+\sum_{k>j} u_{j k}=2+2(m-1) y_{j} . \quad j \in J
$$

(H.4)

$$
\sum_{\substack{i<j \\ i, j \in S}} u_{i j} \leq|S|-1+(m-1) \cdot \sum_{j \in S} y_{j}, \quad \because \quad \forall S \subseteq 1:|S| \geq 2
$$

where $u_{i j}=0,1,2$ is the number of times an arc (undirected) is used in a route. Constraint (H.2) fixes the number of facilities to one, (H.3) states that the degree of a mode is $2 \mathrm{~m}$ if it corresponds to a open facility and 2 otherwise, while (H.4) prevents illegal subtours. 


\section{MODEL IMPLEMEITATION STPATEGY}

The implementation of the modelling approach depends on the nature of the educational facilities being located, availability of school transport, whether schools shut downs are considered or not, type. of constraints to be taken into consideration and objectives assumed to drive the search of optimal policies.

A common strategy may however be identified in several applications consisting of:

1. Definition of the study area - this may be at a national, regional or local scale depending on the facilities being located, attraction areas and degree of interdependence between alternative facilities;

2. Retrieving from database the information required to run the model or models according to the constraints and objectives set up;

3. Optimization phase consisting in exploring several algorithms and optimization procedures in relation with the criteria and constraints considered;

4. Analysis by a planning team of the results generated in the optimization phase to ensure adequacy to reality and add considerations that the optimization procedure has been unable to embrace;

5. Preparing and documenting consistent proposals to submit to political and financial approval;

6. Follow up the implementation of the plan. 


\section{DATA COII ECTISG}

The data collecting in our particular experience at the planning bureau of the Ministry of Education is based upon a relational data base management system which allows storing retrieving, querying and protecting data in a users friendly environment.

Clusters of information regarding educational facilities, students, teachers and other technical administrative staff and educational statistics are considered.

The cluster of educational facilities includes information for every school, such as name, address, postal code, telephone, school type and level, availability of special facilities and a unique index found on the geographical location of the school. Detailed information on buildings and grounds is also stored. The cluster on students includes information on registration, by age groups, classes and success/failure performances from kindergarden to high school. The information is registered by school unit and since this is referred to a geographical based index, a very fine spatial location grid of students by age groups is produced. The cluster on teachers and other staff includes detailed information on academic degrees, previous school related experience and other relevant information for imputation of costs. Finally, the cluster on educational statistics contains information on rates of approval and failure by grade, rates of premature school leaving, average size of classes, average number of students by teacher, etc., and many demographic and social indicators needed for school population forecasting.

Loading information into the datahuse is a huge task demanding careful planning and long term persistance. A project involving the survey of schools, buildings, spaces and equipments assigned to educational activities at a national scale has been set up. Routine surveys of school population have been improved to feed the database. Data from the National Institute of Statitistics was transfered and substantial in house information previously dispersed was gathered and copied or inputed into the database.

A menu driven query system has been implemented, as well as procedures for validating and listing data and defining users protections. This overall data management system intends to support planning in the Ministry of Education and provide data consistency to the modeliing efforts previously described. 


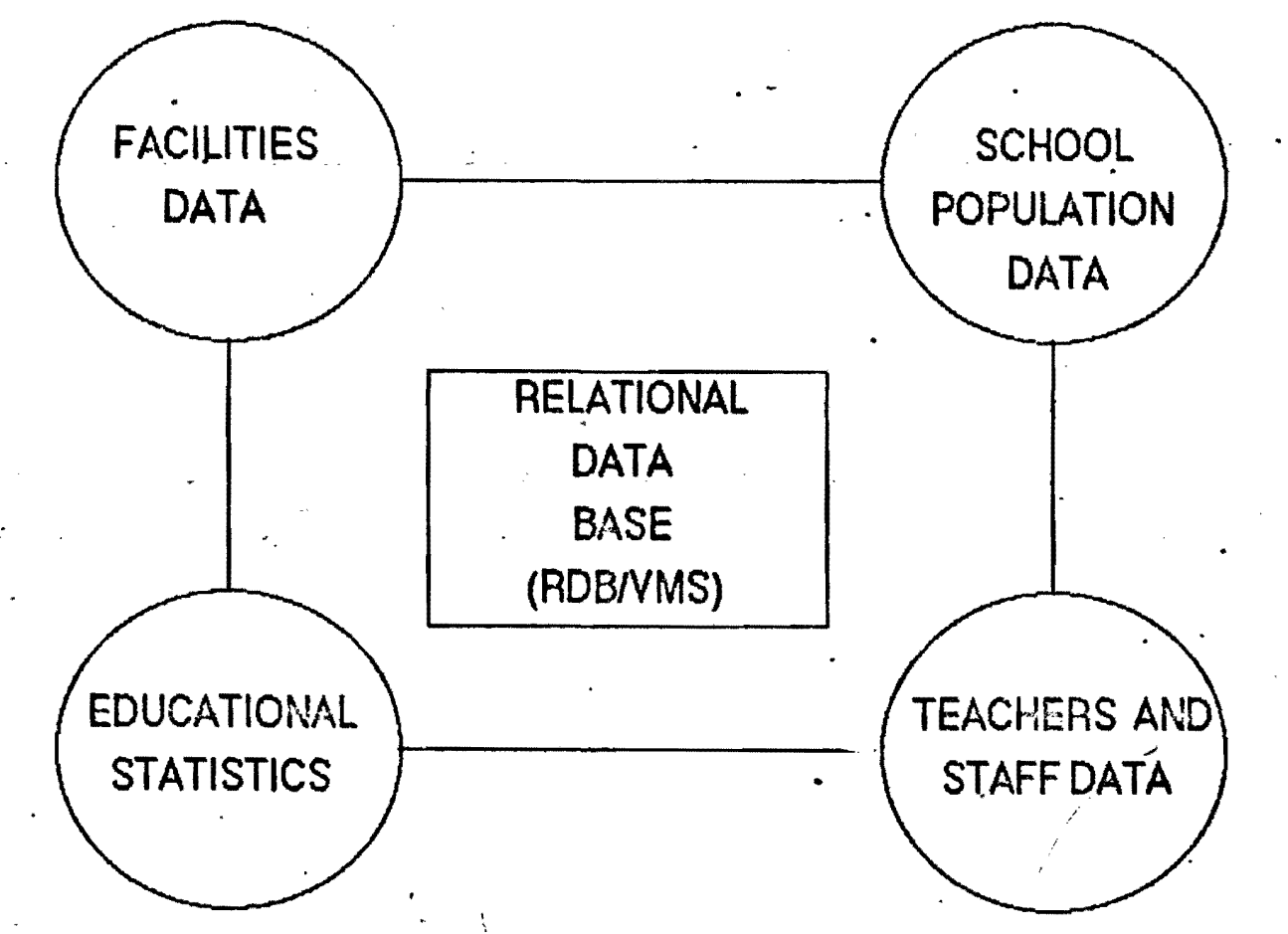

Fig. 3 - Relational Data Base Structure 
The size of the tasks underpinning the optimization of school facilities at a national scilo, and the laree number of bureaucrats that all big organizations tend to attract, for which the Portuguese Ministry of Education is no exception, creates an environment propitious to resistance to changes and growing fears of transfer of power.

- In order to overcome this difficulty it is essential providing careful planning, conveying a substantial amount of effort explaining the usefulness of the approach and to show results fast.

A set of recommendations derived from our experience may be put forward:

1. Try to keep as many tasks as possible with those previously acquainted with them;

2. Whenever possible to decentralize do not hesitate in doing it;

3. Engage in making database users feel part of the project:

4. Stimulate users from other departments to benefit from the stock of information that the database has made available;

5. Provide facilities for querying the database in a users friendly environment;

6. Keep the computer system dedicated exclusively to database management in order to ensure short response time;

7. Search optimality but do not become slave of it - the uncertainty in data items such as costs and demographic forecasts and the existence of qualitative and political components that the models are unable to absorb. advocates precaution in proclaiming optimality;

8. Make all optimal model solutions pass through the sieve of common sense and the expertise of planners of different disciplines such as architects, urban planners, geographers and teachers; 
9. Stand the project as a global integrated one and not as a project of the small team that has eventually had the opportunity of starting it. 


\section{REFERENCES}

AKINC, V. and KHUMAWALA, B.M. (1974), "An Efficient Branch and Bound Algorithm for the Capacitated Warehouse Location..Problem", Graduate School of Business Administration, University of North Carolina.

ALMEIDA, M.T., PAIXÃO, J.P. and COELHO, J.D. (1982), "Aplicaçס̋es dos Problemas de Cobertura e Partição de um Conjunto", Economia, vol. 6, pp. 22-54.

BALAS, E. and PADBERG, M.T. (1972), "On the Set Covering Problem II: An Algorithm", Management Sciences Research Report n? 295, Carnegie Mellon University.

BALINSKI, M.L. (1961), "Fixed Cost Transportation Problems", Naval Research Logistics Quarterly, vol. 8, pp. 41-54.

BILDE, 0. and KRARUP, J. (1977). "Sharp Lower Bounds and Efficient Algorithms for the Simple Plant Location Problem", Annais of Discrete Mathematics, vol. 1, pp. 78-87.

BRANCO, I.M. and COELHO, J.D. (1984), "Formulaçóes Matemạticas da p-Mediana Hamiltoneana", Centro de Estatistica e Aplicaçóes da Universidade de Lisboa, Nota $n^{2} 10 / 84$.

BRANCO, I.M. and COELHO, J.D. (1986), "The Hamiltonean P-Median Problem", Faculdade de Economia, Universidade Nova de Lisboa, WP 59, Paper presented at EURO VII, Lisbon. Subinitted for publication.

CAPTIVO, M.E. (1988), "Algoritmos para o Problema da P-Mediana", Ph.D. Thesis, Universidade de Lisboa.

CHRISTOFIDES, N. and HEY, A.M. (1978), "Lower Bounds for the Set Covering Problem from Network Flow Relaxation", Imperial College of Science and Technology, Dept. of Management Science.

CHURCH, R. and REVELLE, C. (1974), "The Maximal Covering Location Problem", Papers of the Regional Science Assaciation, vol. 32, pp. 101-18. 
COELHO, J.D. (1980), "A Locational Surplus Maximization Approaçh to Public Facility Location", Methods of Operations Research, 40, pp. 265-269." .

COELHO, J.D. (1983), "Formulação em Programação Matenática do Modelo Gravitacional e sua Interpretaçao Económica", Economia, 7, pp. 471-517.

COELHO, J.D. (1038), "Surplus Maximization Caracitated Facility Location Model - A Report"; Forthcoming.

ERLENKOTTER, D. (1978), "A Dual-Based Procedure for Uncapacitated Facility Location", Operations Research, vol. 26 (6), pp..992-1009.

ERLENKOTTER, D. and LEONARDI, G: (1981), "Facility Location with Spatially-Interactive Travel Behavior", Western Management Science Institute, University of California, Los Angeles.

FELDMAN, E., LEHRER, F.A. and RAY, T.L. (1966), "A Warehouse Location under Continuous Economies of Scale", Management Science, vol. 12, pp. 620-684.

GEOFFRION, A. and MCBRIDE, R. (1978), "Lagrangean Relaxation Applied to Capacitated Facility Location Problems", AIIE Transactions, vol. 10(1), pp. 40-47.

HAKIMI, S. (1964), "Optimum Locations of Switching Centers and the Absolute Centers and Median of a Graph", Operations Research, vol. 12, pp. 450-461.

KUEHN, A.A. and HAMBURGER, M.J. (1963), "A Heuristic Program for Locating Warehouses", Management Science, vol. 9(4), pp. 643-666.

LAPORTE, G. (1987), "Location-Routing Prótems", Université de Montréal, Centre de Recherche sur les Transports, Publication \#506.

LAPORTE, G, and NOBERT, Y. (1981), "An Exact Algorithm for Minimizing Routing and Operating Costs in Depot Location", European Journal of Operational Research, vol: 6, pp. 224-226.

LEONARDI, G. (1978), "Optimum Facility Location by Accessibility Maximizing", Environment and Planning A, 10, pp. 1287-1305.

LEONARDI, G. (1981), "The Use of Random-Utility Theory in Building Location Allocation Models", International Institute for Applied Systems Analysis, Laxenburg, Austria, WP-81-28. 
PAIXA0, J.P. (1983), "Algorithms for Large Scale Set Covering Problems", Ph.D. Thesis, Imperial College, University of London.

PIERCE, J.B. (1968), "Application of Combinatorial Programming to a Class of All-zero-one Integer Programming Problems", Management-Science, vol. 15. pp: 191.

REVELLE, C. and SWAIN, R. (1970), "Central Facilities Location", Geographical Analysis, vol. 2, pp. 30-42.

SA, G: (1969), "Branch-and-Bound and Approximate Solutions to the Capacitated Plan-Location Problem", Operations Research, vol. 17, pp. 1005-1016.

TOREGAS, C., SWAIN, R., REVELLE, C. and BERGMAN, L. (1971), "The Location of Emergency Service Facilities", Operations Research, vol. 19, pp. 1363-1367.

VAN ROY, T.J. (1986), "A Cross Decomposition Algorithm for Capacitated Facility Location", Operations Research, vol. 34. pp. 145-163.

WILSON, A.G., COELHO, J.D., MACGILL, S.M. and WILLIAMS, R.C.T.L. (1981), "Optimization in Locational and Transport Analysis", John Wiley \& Sons, New York. 


\section{ULTIMOS WOEKIHG PAFESS EUELICHDOS}

ne 76 - VILAREs. Mamel Jose: "Os Eeno Interuedios Infortados como Eactor de Produçöo". (Julho. 1967).

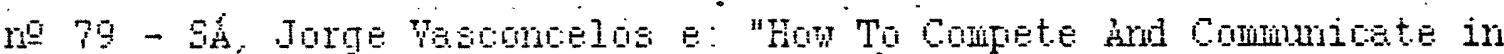
nature Imonstrial Froducts". (Maio. 1906).

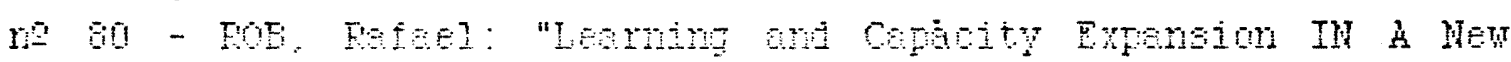
liarket Under Uncertaint". (Fevereiro. 1968)

no 61 - FEREIRA, dlfrejo Marväo: "Gurvey of Ipramio Compatational General Equiliriu Todels For Tax Folioy Evalustion". (Outubro, 1987).

no 82 - SA, Jorge Vasconcelos e: "Everything IS Important: Eut Some Things hre More Important Than others". Maio. $1986)$.

no 83 - EAfCIA. Faula. GASPAR. Vitor e PEFEIRA. Fedro T. "Consuer Theary with Nonconvex Consumption sets". (1010.1969).

ne 84 - CAERL Luis Matine Earata: "Folitica de Préas do sector das Telecomuicacóse: Jua Arelise ae Equilinrio Geral". (Jurha de 1965: Revisto en Haio de 1980).

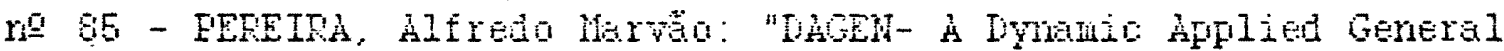
Equilihrium Model For Tax Folicy Evaluation". (Atril, 1986).

ne 66 - D'OREY. Vasco: "On Trade in a Two Country World". (Junho. $1966)$.

no 67 - FEEEIFA. Alfredo Marväo: "Corporate Tax Integration in the United States: A Dyamic Genersl Equilibrium Analyais". (Aluil, 1960 ).

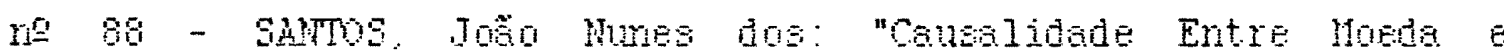
Rendimento na Economia Portuguesa: 1958-1984". (Junho. 1988 ).

ne 89 - GAFMP. Vitar: "Money Heasures of Velfare Change Under Quantity Constranints". (16io, 1988)

ne 90 - SA. Jorge Vasconcellos e: "A Fratical Way to Evaluate Synergy". (Junho, 1968).

ne 91 - EAfCIA. Faula e FAIXAO, I.: "Combining Surrogate Duelity With Eoum Improwing Sequences For Integer Programing". (Jullo. 1966).

ne 92-- CoELHo, Jase Dias: "Optinal Lacation of School Facilities". Julto. 1988)

Quilquer informaçäo sobre os Vorking Fapers ja publicados sera. prestada pelo Secretariado de Apoio aos Docentes, podendo os mesinos ser adquiridos na Seçâo de Vendas da Faculdode de Econonis, un,

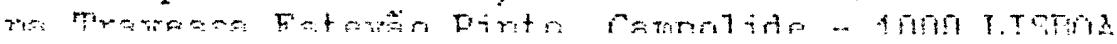

